\title{
Status of blue sheep and Himalayan tahr in Dhorpatan Hunting Reserve, Nepal
}

\begin{abstract}
J. B. Karki ${ }^{1 *}$ and B. B. Thapa ${ }^{1}$
A survey of blue sheep (Pseudois nayaur) was conducted in six blocks of Dhorpatan Hunting Reserve (DHR), Nepal. A total of 852 blue sheep were recorded in 73 different groups. The average group size was found to be 11.7 individuals. The average population density of blue sheep in the reserve was found to be 1.28 animals per $\mathrm{km}^{2}$. There were $263 \mathrm{rams}, 307$ ewes, 89 yearlings and 39 lambs. Among the rams, 126 were classified as trophy rams, 92 as medium rams and 45 as young rams. The ratio of trophy rams to other rams was found to be higher than those found in the earlier studies. The mean sex ratio was 86 males per 100 females and the yearling to ewes ratio was 29 per 100 ewes. The survey of Himalayan tahr (Hemitragus jemlahicus) in Sundaha block recorded 53 individuals with 30 males, 14 females, eight yearlings, and one lamb. The results indicated that the existing quota of blue sheep hunting can be safely continued. In case of higher demands, two more quotas can be added to Barse, Dogadi and Sundaha blocks for the next five years (2008-2012). Himalayan tahrs can be hunted in all the blocks. Sundaha block can sustain four while the rest of the blocks can sustain two Himalayan tahrs per year.
\end{abstract}

Key words: Blue sheep, Dhorpatan Hunting Reserve, Himalayan tahr, hunting quota, population density

D horpatan Hunting Reserve (DHR) established in $1987\left(1,325 \mathrm{~km}^{2}\right)$, encompasses $26.42 \%$ area of Baglung, $14.13 \%$ area of Myagdi and $59.45 \%$ area of Rukum districts of western Nepal. The reserve has dominant rangeland $\left(444.56 \mathrm{~km}^{2}\right)$ followed by forest $\left(426.60 \mathrm{~km}^{2}\right)$ and barren land $\left(426.35 \mathrm{~km}^{2}\right)$ with small area of agricultural land $\left(26.38 \mathrm{~km}^{2}\right)$ and shrub land $\left(1.11 \mathrm{~km}^{2}\right)$.

It is the only reserve in Nepal that allows blue sheep (Pseudois nayaur) hunting. Popularity of blue sheep hunting is growing among the international hunters due to its recognition by Safari Club International as one of the 14 species of wild sheep to receive the Super Slam title (Bajimaya et al., 1990).

Hunting of blue sheep in DHR was continued till 22 April, 1998 but was stopped when sport hunting was disallowed in the area because of conflict. The status of blue sheep was unknown since 1998 and thus, the prime objective of this study was to estimate the blue sheep population along with other game animals of the designated blocks in DHR in order to determine whether the existing quota could be continued. This was essential for two reasons: to issue license and, to fix the quota.

\section{Materials and methods}

Study area

The survey was carried out in six blocks: Sundaha, Seng, Dogadi, Gustung, Barse and Phagune, covering $587.5 \mathrm{~km}^{2}$. The boundary of the blocks mostly followed natural features. The important features of DHR include extensive high land pastures mostly above 3,800 $\mathrm{m}$ and, east-west ridges that make north and south slopes suitable for summer and winter habitats. The highland pastures, which are locally known as Buki, provide summer grazing grounds for livestock (cow, buffalo, goat, and sheep). Below such Buki, temperate forests dominated by blue pine, fir, Quereus spp., rhododendron, birch, and hemlock are found between $3,000 \mathrm{~m}-3,800 \mathrm{~m}$.

\section{Survey method}

A survey was conducted for blue sheep and Himalayan tahr in DHR during 25 May - 12 June, 2007. The survey was conducted by visiting potential habitats in all six blocks. Direct count was done with the help of binocular $(10 * 40$ and $12 * 50)$ and telescope. Counting by sex and age was attempted. Group composition according to Schaller classification (1973) was followed. Only the total numbers were recorded, as classifying them into sex and age was difficult.

\footnotetext{
${ }^{1}$ Department of National Parks and Wildlife Conservation, Babarmahal, Kathmandu

*Corresponding author: jbkarki@gmail.com
} 
Major emphasis was given on counting the whole sub-populations of blue sheep for estimating the minimum number of trophy rams as well as for determining population structure of the group in each block. Due to the lack of quantitative data on population growth trend, recruitment dynamics were analyzed on the basis of following assumptions:

- Stable age distribution (Caughley, 1966)

- Sex ratio of male yearlings to female yearlings is 1

- No change in age specific mortality rate

- Mortality rate is same in all the three male age classes

- Recruitment and survival rates of young are constant and

- No rams survive at the age of 15 years (Chenrnyavskij, 1962)

At first, the number of rams produced in each block was estimated. Then, the estimated annual blue sheep quota was assessed with the existing quota for the sustainable harvest of blue sheep. The ratio of lambs to adult ewes was used to estimate net recruitment rate. The difference between the number of lambs and yearlings was used to calculate intervening mortality. The mortality in the male segment from yearling to trophy age was used to determine the recruitment rate of trophy ram. Efforts were also made to search carcasses.

For the Himalayan tahr (Hemitragus jemlabicus), popularly known as Jharal, male was classified into adult, sub-adult and young; while female into adult, yearling and lamb. Sightings of other wild animals were also recorded. In order to minimize personal biases that may occur while estimating males' horn lengths and yearlings' heights versus those of ewes and youngs, only one single observer was assigned for counting in one group. Other team members assisted the observer to verify the results.

\section{Results and discussion}

\section{Population of Blue sheep}

For counting purpose, $65 \%$ of potential blue sheep areas were surveyed in Sundaha, Dogadi, Barse, Phagune and Gustung blocks. A total of 852 blue sheep were counted in 73 different groups in six blocks. Of them, $81.92 \%$ were classified into different age and sex groups. The average group size of the blue sheep was found to be 11.7 individuals per group (Table 1). This size is more or less the same as reported by Wilson (1981) and Wegge (1976) but smaller as reported by Bajimaya et al. (1990). The group size ranged from 2 to 79 individual animals.

\section{Density of Blue sheep}

The area of the blocks surveyed was expected to contain more blue sheep than what has been observed. However, the actual area inhabited by sheep was far less than the total area of the reserve. Thus, $50 \%$ of the area of the six blocks $\left(587.5 \mathrm{~km}^{2}\right)$ was used for this estimation. The average population density of blue sheep in the reserve was found to be 1.45 (ranging from $0.38-3.60$ ) animals per $\mathrm{km}^{2}$ (Table 1). The mean density was found to be similar to Wegge (1976) but lower compared to Bajimaya et al. (1990).

Phagune and Seng blocks were found to have the lowest apparent density (below one animal per $\mathrm{km}^{2}$ ) whereas Dogadi block had the highest density of 3.59. The result was consistent with that of Bajimaya

Table 1: Sighted number of groups and individuals of blue sheep in each block of DHR

\begin{tabular}{lccccc}
\hline Block & Area $\left(\mathrm{km}^{2}\right)$ & $\begin{array}{c}\text { No. of groups } \\
\text { of }\end{array}$ & $\begin{array}{c}\text { No. of blue } \\
\text { sheep observed }\end{array}$ & $\begin{array}{c}\text { Average group } \\
\text { size }\end{array}$ & $\begin{array}{c}\text { Average apparent } \\
\text { density }\end{array}$ \\
\hline Sundaha & 145 & 10 & 98 & 9.8 & 1.35 \\
Seng & 138 & 5 & 40 & 8 & 0.58 \\
Dogadi & 199 & 29 & 358 & 12.3 & 3.60 \\
Gustung & 167 & 11 & 128 & 11.6 & 1.53 \\
Barse & 201 & 11 & 167 & 15.1 & 1.66 \\
Phagune & 325 & 7 & 61 & 8.7 & 0.38 \\
Total & $\mathbf{1 , 1 7 5}$ & $\mathbf{7 3}$ & $\mathbf{8 5 2}$ & $\mathbf{1 1 . 7}$ & $\mathbf{1 . 4 5}$ \\
\hline
\end{tabular}


et al. (1990) which showed Phagune and Dogadi as having the lowest and the highest apparent densities respectively. The average density might be higher than the calculated apparent density because the team was unable to count all sub-populations of each block.

\section{Productivity of blue sheep}

Only 39 of 307 adult ewes were observed with lambs. Though four lambs were seen with two adult ewes, the team could not consider them twins for the reason that other adult ewes too were seen at a distance of about $200 \mathrm{~m}$ apart in the same area. The mean recruitment rate was estimated to be $12.75 \%$ (Table 2). Since the team was unable to determine the number of lambs born alive, the ratio of the number of observed lambs to 100 ewes was taken as recruitment rate. The mean recruitment rate was found to be lower than the rate reported by Bajimaya et al. (1990). The disparity could have occurred because of timing of this survey, which was conducted within the lambing period. It may be that the pregnant females had not given birth during the survey period. It can also be speculated that the survey had missed those pregnant females who went away leaving the group to give birth.

No new born lambs were observed in Sundaha and Seng blocks (Survey period: June 1-5). The maximum of lamb to adult ratio was observed in Dogadi block (Survey period; June 6-10) with 28\% recruitment rate (Table 2 ).

\section{Population trend of blue sheep}

Out of the 698 animals that were classified into age and sex, 263 (37.68\%) were rams, 307 (43.98\%) were ewes, $89(12.75 \%)$ were yearlings and 39 (5.59\%) were lambs. Of the 263 rams, 126 were classified as trophy rams, 92 as medium rams and 45 as young rams (Table 2). The recorded proportion of trophy rams was found to be higher than those recorded by the earlier studies. This may be due to the suspension of the trophy hunting for more than seven years (1998-2006) in DHR. The recorded proportions of young rams were less compared to those recorded in the earlier studies. One of the plausible explanations for this could be that many young males with smaller horn size might have been mistakenly classified as adult females.

The mean sex ratio was found to be 86 males per 100 females. The male ratio recorded was lower than what Bajimaya et al. (1990), and Wegge (1976), had recorded and higher than what Wilson (1981) had reported. Recording of higher number of females in this study could be due to the higher proportion of total animals classified. High degree of variation in sex ratios existed when compared between blocks, ranging from only 33 in Seng block to 129 in Dogadi block (Table 3). This is in conformity with the studies of Bajimaya et al. (1990), Wegge (1976) and Wilson (1981). The yearling to 100 ewes' ratio was found to be 29. This ratio is less than the ratios mentioned in the earlier studies by Bajimaya et al. (1990), Wilson (1981) and Wegge (1976).

Table 2: Group composition of blue sheep in 6 blocks in DHR

\begin{tabular}{|c|c|c|c|c|c|c|c|c|c|c|c|c|c|c|c|c|}
\hline \multirow[t]{3}{*}{ Block } & \multirow{3}{*}{ 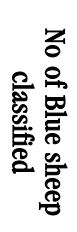 } & \multirow{2}{*}{\multicolumn{2}{|c|}{$\begin{array}{c}\text { Class III } \\
\text { (Trophy ram) }\end{array}$}} & \multirow{2}{*}{\multicolumn{2}{|c|}{$\begin{array}{c}\text { Class II } \\
\text { (Medium ram) }\end{array}$}} & \multirow{2}{*}{\multicolumn{2}{|c|}{$\begin{array}{c}\text { Class I } \\
\text { Young ram) }\end{array}$}} & \multirow{2}{*}{\multicolumn{2}{|c|}{ Ewes }} & \multirow{2}{*}{\multicolumn{2}{|c|}{ Yearling }} & \multirow{2}{*}{\multicolumn{2}{|c|}{ Lamb }} & \multirow{3}{*}{$\begin{array}{c}\text { Sex } \\
\text { ratio } \\
(M: F)\end{array}$} & \multirow{3}{*}{$\begin{array}{l}\text { Yrl:F } \\
\text { ratio }\end{array}$} & \multirow{3}{*}{ 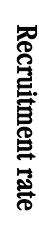 } \\
\hline & & & & & & & & & & & & & & & & \\
\hline & & No. & $\%$ & No. & $\%$ & No. & $\%$ & No. & $\%$ & No. & $\%$ & No. & $\%$ & & & \\
\hline \multirow{2}{*}{$\begin{array}{l}\text { Sundaha } \\
\text { Seng }\end{array}$} & \multirow{2}{*}{$\begin{array}{l}42 \\
15\end{array}$} & 8 & 19.05 & 5 & 11.90 & 2 & 4.76 & 21 & 50 & 6 & 14.29 & 0 & 0 & 71 & 29 & 0 \\
\hline & & 2 & 13.33 & 1 & 6.67 & 0 & 0.00 & 9 & 60 & 3 & 20.00 & 0 & 0 & 33 & 33 & 0 \\
\hline Dogadi & 299 & 62 & 20.74 & 39 & 13.04 & 23 & 7.69 & 98 & 32.78 & 49 & 16.39 & 28 & 9.36 & 127 & 50 & 29 \\
\hline Phagune & 61 & 6 & 9.84 & 10 & 16.39 & 1 & 1.63 & 29 & 47.54 & 11 & 18.03 & 4 & 6.56 & 59 & 38 & 14 \\
\hline Barse & 158 & 30 & 18.99 & 20 & 12.66 & 13 & 8.22 & 79 & 50.00 & 13 & 8.23 & 3 & 1.90 & 80 & 16 & 4 \\
\hline Gustung & 123 & 18 & 14.63 & 17 & 13.82 & 6 & 4.87 & 71 & 57.72 & 7 & 5.69 & 4 & 3.25 & 58 & 10 & 6 \\
\hline Total & 698 & 126 & 18.05 & 92 & 13.18 & 45 & 6.45 & 307 & 43.98 & 89 & 12.75 & 39 & 5.59 & & & \\
\hline
\end{tabular}


For the same area, the total population estimated by different studies is different. For instance, Bajimaya et al. (1990) estimated 1,346 animals, whereas Wegge (1976) estimated 575-630 in five blocks excluding Sundaha. Similarly, Wilson (1981) estimated 800-900 animals. This study observed at least 852 individuals in about $60 \%$ of the potential blue sheep habitat. This is similar to the observations made by Wilson (1981) and Wegge (1976) but slightly lower than that made by Bajimaya et al. (1990) (Fig. 1).

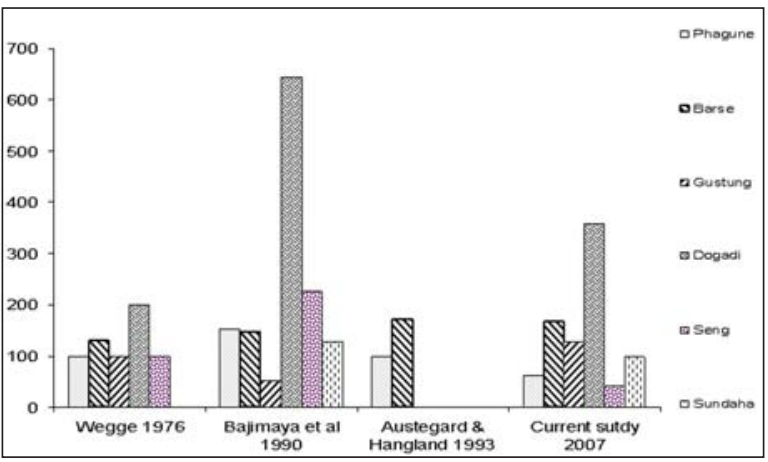

Fig 1: Comparison of blue sheep number with earlier studies in DHR

In general, it can be interpreted that the surveyed blocks contained healthy population of blue sheep with enough numbers; particularly the trophy rams. The numbers are adequate to sustain the existing quota. In some blocks, the quota can be increased to some extent for harvesting without disturbing the present trend of population growth of blue sheep, and reducing the proportion of trophy ram in population. block, blue sheep were found in maximum number with higher group size and apparent density. Gustung block, on the other hand, has shown that population is better than indicated by the earlier studies. Dogadi block followed by Sundaha block and Barse block has higher proportion of trophy rams. This implies that these blocks can support one or two additional quota provided demands are raised, and the remaining blocks can sustain the existing quota safely.

\section{Blue sheep quota}

The Department of National Parks and Wildlife Conservation (DNPWC) has allocated 26 blue sheep as an annual quota for hunting in DHR. The quota has never been fully utilized in any year between the period of 1980 to 1990 (Table 3). According to the records, a maximum of $50 \%$ of the annual quota seems to have been utilized in 1992/93 and the minimum $19.2 \%$ in $1997 / 98$. While considering blocks, a maximum of $61.1 \%$ of the annual quota has been utilized in Dogadi block followed by 37.5\% in Seng block. Except Dogadi and Seng blocks, the rest of the four blocks could be utilized for only $25 \%$ of the annual quota of blue sheep. On an average, only about one third of the annual quota seems to have been utilized in six years $(1992 / 93$ 1997/98). The trend of use of annual blue sheep quota seems to have reduced from average two third between 1980 and 1990 to only one third between 1992 and 1998.

The condition of Dogadi block was better in terms of distribution and number of blue sheep. In this

Table 3: Number of blue sheep harvest (1992/93-1997/98) on different blocks in DHR

\begin{tabular}{|c|c|c|c|c|c|c|c|c|c|c|}
\hline \multirow[t]{2}{*}{ Block } & \multicolumn{9}{|c|}{ Blue sheep harvest } & \multirow{2}{*}{$\begin{array}{l}\% \text { of } \\
\text { harvest }\end{array}$} \\
\hline & $\begin{array}{c}\text { Current } \\
\text { annual } \\
\text { quota }\end{array}$ & $\begin{array}{c}2049 / 50 \\
(1992 / 93)\end{array}$ & $\begin{array}{c}2050 / 51 \\
(1994 / 94)\end{array}$ & $\begin{array}{c}2051 / 52 \\
(1994 / 95)\end{array}$ & $\begin{array}{c}2052 / 53 \\
(1995 / 96)\end{array}$ & $\begin{array}{c}2053 / 54 \\
(1996 / 97)\end{array}$ & $\begin{array}{c}2054 / 55 \\
(1997 / 98)\end{array}$ & $\begin{array}{c}\text { Total } \\
\text { harvest }\end{array}$ & $\begin{array}{c}\% \text { of } \\
\text { harvest }\end{array}$ & \\
\hline Sundaha & 4 & 0 & 0 & 2 & 1 & 3 & 0 & 6 & 25.0 & 57.5 \\
\hline Seng & 4 & 2 & 1 & 0 & 3 & 0 & 3 & 9 & 37.5 & 67.5 \\
\hline Dogadi & 6 & 3 & 5 & 4 & 5 & 3 & 2 & 22 & 61.1 & 76.6 \\
\hline Gustung & 4 & 2 & 0 & 0 & 0 & 4 & 0 & 6 & 25.0 & 82.5 \\
\hline Barse & 4 & 3 & 1 & 1 & 1 & 0 & 0 & 6 & 25.0 & 42.5 \\
\hline Phagune & 4 & 3 & 0 & 1 & 1 & 0 & 0 & 5 & 20.8 & 75.0 \\
\hline Total & 26 & 13 & 7 & 8 & 11 & 10 & 5 & 54 & 34.6 & 67.0 \\
\hline
\end{tabular}

* Between 1980-1990 (Bajimaya et al. 1990)

Source: DNPWC, 2011


Table 4: Number of Himalayan tahr harvest (1992/93-1997/98) in DHR

\begin{tabular}{lllllllll}
\hline Block & $\begin{array}{l}\text { Current } \\
\text { annual } \\
\text { quota }\end{array}$ & $\mathbf{1 9 9 2 / 9 3}$ & $\mathbf{1 9 9 4 / 9 4}$ & $\mathbf{1 9 9 4 / 9 5}$ & $\mathbf{1 9 9 5 / 9 6}$ & $\mathbf{1 9 9 6 / 9 7}$ & $\mathbf{1 9 9 7 / 9 8}$ & $\begin{array}{l}\text { Total } \\
\text { Harvest }\end{array}$ \\
\hline Sundaha & $11-16$ & 0 & 0 & 2 & 1 & 4 & 0 & $\mathbf{7}$ \\
Seng & & 2 & 1 & 4 & 0 & 0 & 4 & $\mathbf{1 1}$ \\
Dogadi & 3 & 0 & 2 & 0 & 0 & 1 & $\mathbf{6}$ \\
Gustung & 2 & 0 & 0 & 0 & 4 & 0 & $\mathbf{6}$ \\
Barse & 2 & 1 & 1 & 0 & 0 & 0 & $\mathbf{4}$ \\
Phagune & & 3 & 1 & 1 & 1 & 0 & 0 & $\mathbf{6}$ \\
Total & $\mathbf{1 1 - 1 6}$ & $\mathbf{1 2}$ & $\mathbf{3}$ & $\mathbf{1 0}$ & $\mathbf{2}$ & $\mathbf{8}$ & $\mathbf{5}$ & $\mathbf{4 0}$ \\
\hline
\end{tabular}

Source: DNPWC, 2011

\section{Himalayan tahr (Jharal)}

The team spent one and a half day in Sundaha block and a half to one day in the rest of the five blocks for surveying Himalayan tahr as well. Altogether 53 Himalayan tahrs were sighted in Sundaha block. They include: thirty males (class III: 16, class II: 13, class I: 1), 14 females, eight yearlings and one lamb. Gender could not be assigned for 11 tahrs of Phagune, three of Barse, one of Seng and another, one of Dogadi blocks.

The sex ratio of 53 classified Jharal was 30:14 (214 male: 100 female). The yearling to female ratio was found to be 5.7 while that of fawn to female at 7 . The existing data, secondary information and the pellet group's observations suggested that Surtibang and Dogadi blocks can sustain annual quotas of four Jharal whereas the rest of the blocks can sustain only two Jharal per year. Formal count of Jharal was not carried out in Surtibang block. However, the study team members made a few informal visits of the block, during which they observed pellet groups of Jharal in many locations. If the demand for Jharal increases, a separate census along with the hunting operation might be conducted to ascertain the status and, fixing the quota.

\section{Current Himalayan tahr quota}

Wegge (1976) recommended that 11 -16 Himalayan tahrs could be harvested in irregular intervals. In six years period (1992/93-1997/98), 40 Himalayan tahrs have been used on a regular basis (Table 4). On an average, about seven (44\%) Himalayan tahrs have been harvested and the maximum hunting was 12 $(75 \%)$ in 1992/93 and 10 in 1994/95. More than six Himalayan tahrs seem to have been utilized in Seng and Sundaha blocks alone, in a period of six years from 1992/93 to $1997 / 98$ (on an average one Himalayan tahr per year).

The use of Jharal quota has been recorded as 100\% in 2008/09, 61\% (11 in number) in 2009/10 and 28 $\%$ (five in number, for half season) in 2010/11 (Table 5). If the quota for Surtibang block is assumed as two, then the year 2008/09 becomes the first time when all $100 \%$ quota of Jharal was used. However, it was discontinued after 2009/10.

Table 5: Number of blue sheep and Himalayan tahr harvest (2008/09-2010/11) on different blocks in DHR

\begin{tabular}{|c|c|c|c|c|c|c|}
\hline \multirow[t]{2}{*}{ Block } & \multicolumn{2}{|c|}{$2008 / 09$} & \multicolumn{2}{|c|}{$2009 / 10$} & \multicolumn{2}{|c|}{$2010 / 11$ as of Feb 28,2011} \\
\hline & $\begin{array}{l}\text { Blue } \\
\text { sheep }\end{array}$ & $\begin{array}{l}\text { Himalayan } \\
\text { tahr }\end{array}$ & $\begin{array}{l}\text { Blue } \\
\text { sheep }\end{array}$ & $\begin{array}{l}\text { Himalayan } \\
\text { tahr }\end{array}$ & $\begin{array}{l}\text { Blue } \\
\text { sheep }\end{array}$ & Himalayan tahr \\
\hline Sundaha & 5 & 2 & 0 & 0 & 4 & 2 \\
\hline Seng & 0 & 0 & 0 & 0 & 0 & 0 \\
\hline Dogadi & 4 & 1 & 0 & 0 & 2 & 2 \\
\hline Gustung & 10 & 6 & 0 & 0 & 0 & 0 \\
\hline Barse & 5 & 2 & 6 & 2 & 1 & 0 \\
\hline Phagune & 5 & 5 & 2 & 0 & 2 & 1 \\
\hline Surtibang & 1 & 2 & 2 & 9 & 0 & 0 \\
\hline Total & 30 & 18 & 10 & 11 & 9 & 5 \\
\hline
\end{tabular}

Source: DNPWC, 2011 
The survey of Himalayan tahr conducted in Sundaha block recorded a minimum of 16 mature males of harvestable size. The maximum harvest was four Himalayan tahrs in 1996/97. Sundaha block can sustain annual harvest of four Himalayan tahrs. It is suggested that only two males be allowed for harvest in each season (March/April) and (October/ November) to reduce any disturbances.

Signs, secondary information, occasional observation data and the demand situation suggested that each block can sustain two Himalayan tahrs per year. It is recommended that in coming years, a comprehensive survey be carried out along with the hunting operation in all blocks, except Sundaha. This will help in supplementing existing available information about the status of Himalayan tahr.

\section{Conclusion and recommendations}

The existing quota of blue sheep hunting, six in Dogadi and four each in the rest of the five blocks can be safely continued. In case of higher demands, two more quotas can be added to Barse, Dogadi and Sundaha blocks for the next five years. Himalayan tahrs can be hunted in all the blocks. Sundaha can sustain four and the rest of the blocks can sustain two Himalayan tahrs per annum. The full use of prescribed quotas has been found to be used only once, in 2008/09.

Only $50 \%$ of the total quota per annum should be permitted to be harvested in each season so as to reduce physical disturbances caused by hunting. Repeated hunting during the same season should not be continued in the same area of the block. If new companies are interested, Surtibang block could be considered as a place to be allowed for Himalayan tahr hunting.

Regular census is important to plan sustainable harvest; thus, counting one block each year to complete all the six blocks in a period of six years could be reasonable for practicing regular census. It will be better if the census could be carried out during the hunting operation as because necessary supports could be obtained from hunting companies. To supplement, a regular blue sheep and Himalayan tahr count programme could be planned from the Government budget so as to make DHR capable of monitoring changes due to hunting. On the other hand, DHR should be equipped with necessary logistic material like sleeping bags, tents, and instruments like binocular, digital camera, Global Positioning System (GPS) and telescope with stand. In addition, Game Scouts, Senior Game Scouts and Rangers should be trained on counting, sexing and aging of blue sheep and Himalayan tahr.

Involvement of local people in the management of sport hunting is essential. Therefore, to increase their stake, Reserve and the outfitters should initiate schemes that provide financial support to the concerned local communities. They should also assist local communities to use funds appropriately both in conservation as well as in income generating activities.

\section{References}

Bajimaya, S., Baral, N. and Yadav, L. B. 1990. Report on Overall Assessment of Dhorpatan Hunting Reserve. Department of National Parks and Wildlife Reserve, Kathmandu, Nepal.

Caughley, G. 1966. Mortality patterns in mammals. Ecology 47: 906-918.

Chenrnyavskij, F.B. 1962. On the reproduction and growth of the snow sheep (Ovis nivicola Esch.) Zool Zh.41 (10): 1556-1566.

DNPWC. 2011. Hunting Records of Dhorpatan Hunting Reserve. Department of National Parks and Wildlife Reserve, Babarmahal, Kathmandu, Nepal.

Schaller, G. B. 1973 . Observation on Himalayan tahr (Hemitragus jemlabicus). Journal of Bombay Natural History Society 70 (1): 1-24.

Wegge, P. 1976. Himalayan Shikar Reserves: Surveys and Management Proposals. FAO Field Document No.5.

Wilson, P. 1981. Ecology and habitat utilization of Blue sheep Psendios nayaur in Nepal. Biological Conservation 21: 55-74. 